\title{
Estudo da adsorção de surfactante catiônico em uma matriz inorgânica preparada via óxido de nióbio
}

\section{(Adsorption study of the cationic surfactant in inorganic matrices prepared from niobium oxides)}

\author{
P. H. F. Pereira, M. L. C. P. da Silva \\ Departamento de Engenharia Química, EEL/USP, Rod.Itajubá-Lorena km 74,5, C.P. 116, Lorena, SP 12600-000 \\ mlcaetano@dequi.eel.usp.br
}

\begin{abstract}
Resumo
Uma aplicação que vem sendo estudada para o nióbio na forma de fosfato hidratado é no processo de adsorção. Os fosfatos são constituídos por cristais lamelares, o que possibilita a utilização em processo de adsorção de moléculas polares como o surfactante catiônico brometo de cetiltrimetilamônio (CTAB). Este trabalho descreve o estudo da adsorção do surfactante CTAB em uma matriz preparada a partir do óxido de nióbio. O adsorvente preparado foi caracterizado por difração de raios X, termogravimetria, microscopia eletrônica de varredura acoplada a um espectrômetro de dispersão de energia e por análise de área superficial específica. Para o estudo de adsorção utilizaram-se isotermas de Langmuir e de Freundlich. No processo de adsorção variou-se o pH, podendose observar melhor quantidade adsorvida em $\mathrm{pH} 3,0 \mathrm{com} \mathrm{Q}_{0}=16,52 \mathrm{mg} \cdot \mathrm{g}^{-1}$. O processo de adsorção mostrou comportamento favorável para o modelo de Langmuir e desfavorável para o modelo de Freundlich.

Palavras-chave: adsorção, isoterma de Langmuir, isoterma de Freundlich.
\end{abstract}

\begin{abstract}
One of the applications that have been studied for niobium is the adsorption process, in the form of hydrous phosphates. These materials are constituted of lamellar crystals, what make them possible to be used in adsorption processes and polar molecules intercalation as the cationic as the cationic surfactant cetyltrimethyammonium bromide (CTAB). This work describes the adsorption study for cationic cetytrimetlyl ammonium bromide (CTAB) surfactant in the niobium oxide matrix. The material was characterized by X-ray diffraction, thermogravimetry, scanning electron microscopy and surface area measurements. The Langmuir and Freundlich isotherm models were used for the CTAB adsorption study. In the adsorption process the pH effect has been studied and it could be observed that the largest adsorption value was in $\mathrm{pH} 3.0$ with $Q_{o} 16.52 \mathrm{mg} / \mathrm{g}$. The adsorption process was favorable for the Langmuir model and not favorable for the Freundlich one.
\end{abstract}

Keywords: adsorption, Langmuir isotherm, Freundlich isoterm.

\section{INTRODUÇÃO}

O crescente interesse pelo nióbio está relacionado com seus múltiplos usos para produção de materiais de alta tecnologia. No campo da metalurgia, o nióbio é utilizado na fabricação de ligas metálicas para utilização em temperaturas elevadas [1] e na catálise é usado para modificar a fotossensibilidade, acidez ou redutibilidade dos materiais catalíticos [2]. O óxido de nióbio $\mathrm{V}$, quando fundido com metais alcalinos, forma niobato alcalino. Óxido de nióbio $(\mathrm{V})$ hidratado ou hidróxido de nióbio $\mathrm{V}$ é formado quando soluções ácidas contendo nióbio são neutralizadas ou quando niobatos de metais alcalinos são tratados com ácidos [3]. O óxido de nióbio $\mathrm{V}$ tem sido muito utilizado em lentes oftálmicas diminuindo a espessura e o peso. Estudos sobre seu comportamento catalítico e em troca iônica vêm sendo realizados [4-6].
A pesquisa para encontrar materiais sintéticos que apresentem propriedades de troca iônica tem levado ao estudo do comportamento de alguns fosfatos de metais de transição, tais como de: zircônio, tório, cromo, titânio e nióbio [7, 8]. Entre esses materiais, destaca-se o óxido de nióbio hidratado que pode ser facilmente obtido pela fusão do pentóxido de nióbio com carbonato de potássio, formando niobato de potássio e posterior precipitação em solução de ácido nítrico de concentração adequada $[9,10]$. Outra alternativa viável para obtenção do óxido de nióbio hidratado é por precipitação em solução homogênea usando como agente precipitante a uréia e o carbonato de amônio $[5,11]$. Observou-se que o precursor do agente precipitante na obtenção do óxido de nióbio hidratado influencia nas propriedades físico-químicas gerando material com maior ou menor grau de hidratação e cristalinidade [5]. Recentemente foi estudada a utilização do óxido de nióbio hidratado como suporte para imobilização 
da enzima lipase e sua posterior aplicação em reações de biotransformação de óleos vegetais com o objetivo de agregar valor as matérias-primas da agroindústria nacional visando a obtenção de biodiesel [12]. Diversos materiais vêm sendo pesquisados como adsorvente em surfatantes, onde estão incluídos os hidróxidos duplos lamelares, zeólitas, alumina [13-15] e polímeros [16].

Com o intuito de desenvolver materiais com propriedades adequadas para serem usados como adsorventes, o grupo de Novos Materiais da EEL/USP vem preparando compostos para aplicação na adsorção de íons e moléculas em matrizes inorgânicas. Os graves problemas ambientais gerados pelo aumento dos descartes de efluentes industriais e domésticos contendo surfatantes, aliados as leis ambientais cada vez mais rigorosas, estimulam as pesquisas para a preparação de novos materiais com propriedades adsorventes. $\mathrm{O}$ estudo do processo de adsorção foi feito utilizando-se modelos teóricos. Dentre os modelos de adsorção com ligações químicas estudadas, os que mais se aplicam aos fenômenos de adsorção líquidos-sólidos são os modelos de Langmuir e de Freundlich [17]. Esses modelos são os mais freqüentemente usados para descrever isotermas para aplicações em tratamento de águas e de efluentes [18-21].

A análise dos dados da isoterma é importante para desenvolver uma equação que represente realmente os resultados e que possa ser usada para propósitos de dimensionamento de equipamentos a serem utilizados na remoção de poluentes.

A expressão linear de Langmuir é dada pela equação (A):

$$
\mathrm{C}_{\mathrm{e}} / \mathrm{q}_{\mathrm{e}}=1 / \mathrm{Q}_{\mathrm{o}} \cdot \mathrm{b}+\mathrm{C}_{\mathrm{e}} / \mathrm{Q}_{\mathrm{o}}
$$

sendo $\mathrm{C}_{\mathrm{e}}$ a concentração do surfatante no equilíbrio $\left(\mathrm{mg} \cdot \mathrm{L}^{-1}\right)$, $\mathrm{q}_{\mathrm{e}}$ a quantidade adsorvida $\left(\mathrm{mg} \cdot \mathrm{g}^{-1}\right), \mathrm{Q}_{\mathrm{e}}\left(\mathrm{mg} \cdot \mathrm{g}^{-1}\right)$ e $\mathrm{b}\left(\mathrm{L} \cdot \mathrm{mg}^{-1}\right)$ constantes relacionadas com a capacidade de adsorção máxima e energia de adsorção, respectivamente.

$\mathrm{O}$ gráfico linear $\mathrm{C}_{e} / \mathrm{q}_{e}$ vs $\mathrm{C}_{\mathrm{e}}$ confirma a validade do modelo de Langmuir para o processo. A equação de reta obtida apresenta coeficiente angular correspondente a $1 / \mathrm{Q}_{0}$ e coeficiente linear correspondente a $1 / \mathrm{Q}_{0} \mathrm{~b}$. A característica essencial da isoterma pode ser expressa pela constante adimensional chamada parâmetro de equilíbrio, a qual é definida pela equação B:

$$
\mathrm{R}_{\mathrm{L}}=1 / 1+\mathrm{bC}_{\mathrm{o}}
$$

sendo Ce a concentração inicial do surfatante mais alta em ( $m g . \mathrm{L}^{-1}$ ) e b a constante de Langmüir. $\mathrm{O}$ valor de $\mathrm{R}_{\mathrm{L}}$ entre 0 e 1 indica adsorção favorável.

A forma linear da equação de Freundlich é dada pela equação C:

$$
\log \mathrm{q}_{\mathrm{e}}=\log \mathrm{K}_{\mathrm{f}}+1 / \mathrm{n} \log \mathrm{C}_{\mathrm{e}}
$$

sendo $\mathrm{K}_{\mathrm{f}}\left(\mathrm{mg} \mathrm{g}^{-1}\right)$ e $\mathrm{n}$ constantes relacionadas com a capacidade de adsorção. Os valores de $\mathrm{K}_{\mathrm{f}}$ e $\mathrm{n}$ podem ser obtidos pela intersecção e inclinação do gráfico linear de $\log \mathrm{q}_{e} v s \log C_{e}$. $\mathrm{O}$ valor de $\mathrm{n}$ entre 2 e 10 indica adsorção favorável.

A escolha pelo surfatante catiônico CTAB se justifica por ser muito usado nas indústrias químicas aparecendo em vários produtos de limpeza, gerando grandes problemas nas estações de tratamento de efluentes.

O objetivo desse trabalho foi preparar uma matriz inorgânica via óxido de nióbio e posteriormente estudar a adsorção do surfatante catiônico CTAB no composto preparado.

\section{PARTE EXPERIMENTAL}

\section{Preparação do material adsorvente}

A síntese deste composto foi executada baseando-se na metodologia de preparação apresentada por Hahn [22]. Fezse a fusão alcalina do pentóxido de nióbio com carbonato de potássio na proporção 1:5 em cadinho de porcelana. A mistura foi pré-aquecida por $1 \mathrm{~h}$ bico de Bünsen e em seguida realizouse a fusão alcalina em um forno tipo mufla por $6 \mathrm{~h}$ a $900{ }^{\circ} \mathrm{C}$. $\mathrm{O}$ material fundido foi lixiviado com água deionizada fervente e posteriormente adicionou-se uma solução de ácido fosfórico 0,3 mol. $L^{-1}$, sob constante agitação, obedecendo a proporção $\mathrm{Nb}: \mathrm{PO}_{4}(1: 2)$.

\section{Caracterização do material adsorvente}

O material preparado foi caracterizado por difração de raios X (DRX), termogravimetria (TG/DTG), microscopia eletrônica de varredura (MEV) e medida de área superficial específica pelo método BET.

A curva TG foi obtida em uma termobalança Shimadzu TGA-50 em cadinho de platina aberto, com razão de aquecimento $20{ }^{\circ} \mathrm{C} \cdot \mathrm{min}^{-1}$ em $50 \mathrm{~mL} \cdot \mathrm{min}^{-1}$ em fluxo de nitrogênio numa faixa de temperatura entre a temperatura ambiente e $900{ }^{\circ} \mathrm{C}$.

Para a determinação da área superficial específica dos materiais utilizou-se um analisador de adsorção gasosa (Gas Sorption Analyzer), sob atmosfera de nitrogênio com fluxo de $30 \mathrm{~mL} \cdot \mathrm{min}^{-1}$ [23]. Foram feitos ainda dois pré-tratamentos, um a $50{ }^{\circ} \mathrm{C}$ em estufa a vácuo por $16 \mathrm{~h}$ e outro, no próprio porta amostra (célula) a $50{ }^{\circ} \mathrm{C}$ por $3 \mathrm{~h}$ com manta aquecedora.

Os DRX foram obtidos em um difratômetro Rich Seifert com radiação Cuk $\alpha, 30 \mathrm{kV}, 40 \mathrm{~mA}$. A varredura foi feita com passo de $0,05^{\circ}$ variando-se $2 \theta$ entre 10 e $70^{\circ}$.

A fotomicrografia foi obtida em um microscópio eletrônico de varredura (MEV) LEO 1450VP com elétrons secundários, acoplado a um espectrômetro de energia dispersiva (EDS). A amostra foi recoberta com pó de ouro para evitar o seu carregamento e fixada em um porta-amostra com fita carbono autocolante dupla face.

Metodologia de quantificação do surfatante quartenário de amônio $C T A B$

Em $12 \mathrm{mLde}$ CTAB foram adicionados $0,24 \mathrm{~mL}$ de ácido 
pícrico em $\mathrm{NaOH}$ 0,002 mol.L-1 e em seguida, adicionou-se $6,0 \mathrm{~mL}$ do solvente metil-isobutil-cetona (MIBK). Agitou-se a mistura por 5 min para a completa extração do par iônico formado e separou-se a fase orgânica com centrifugação a $3500 \mathrm{rpm}$ durante $5 \mathrm{~min}$. Por meio de um espectrofotômetro UV-visível FEMTO 600 mediu-se a absorbância da fase orgânica a $375 \mathrm{~nm}$.

\section{Definição do tempo de contato entre a solução e a matriz. inorgânica}

$\mathrm{Na}$ definição do tempo de contato entre a matriz inorgânica $(0,15 \mathrm{~g})$ e a solução de CTAB fixou-se a concentração inicial do surfatante em $30 \mathrm{mg} \cdot \mathrm{L}^{-1}$. A solução foi filtrada em filtro de placa porosa e os experimentos foram realizados com tempos de 1, 3, 5 e $7 \mathrm{~h}$. Preparouse a solução de CTAB pesando-se $0,1 \mathrm{~g}$ do surfatante e em seguida avolumou-se em um balão de $100 \mathrm{~mL}$. A partir dessa solução estoque prepararam-se soluções de CTAB em diferentes concentrações entre 10 e $50 \mathrm{mg} . \mathrm{L}^{-1}$. A concentração micelar crítica (CMC) do surfatante CTAB é $7 \mathrm{Mm}$. A quantidade de surfatante adsorvido pela matriz inorgânica foi calculada por meio da equação D.

$$
\mathrm{q}=\mathrm{V}\left(\mathrm{C}_{\mathrm{i}}-\mathrm{C}_{\mathrm{f}}\right) / \mathrm{M}
$$

sendo $C_{i}$ a concentração inicial do surfatante, $C_{f}$ a concentração de equilíbrio do surfatante, $\mathrm{M}$ a massa da matriz inorgânica e V o volume da solução de surfatante.

\section{Estudo da adsorção do surfatante CTAB na matriz. inorgânica}

O estudo da remoção do sal de amônio quaternário CTAB foi realizado utilizando-se o processo descontínuo, colocandose em contato $0,15 \mathrm{~g}$ do material inorgânico com $50 \mathrm{~mL}$ do surfatante na faixa de concentração de 10 a $50 \mathrm{mg} \cdot \mathrm{L}^{-1}$. A faixa de concentração do CTAB estava abaixo da concentração micelar crítica (CMC), para evitar a formação de micelas [20, 21]. Para o estudo do efeito do $\mathrm{pH}$ no processo de adsorção do surfatante na matriz inorgânica fez-se o ajuste do $\mathrm{pH}$ da solução de CTAB em pH 9,6 com solução de $\mathrm{NaOH}(0,1$ mol. $\left.L^{-1}\right)$ e em pH 3,0 com adição de uma solução de $\mathrm{H}_{3} \mathrm{PO}_{4}$ $\left(0,3\right.$ mol.L $\left.{ }^{-1}\right)$.

\section{RESULTADOS E DISCUSSÃO}

Após a preparação do material adsorvente foram feitas algumas caracterizações para comprovação da natureza do material formado.

A Fig. 1A mostra o difratograma de raios $\mathrm{X}$ da matriz inorgânica preparada a partir do óxido de nióbio. A Fig. 1B mostra a matriz inorgânica após tratamento térmico a $600^{\circ} \mathrm{C}$ e a Fig. $1 \mathrm{C}$ o difratograma de raios $\mathrm{X}$ do fosfato de nióbio anidro. Com o resultado do difratograma da matriz inorgânica (Fig. 1A) comparou-se com o padrão JCPDS, observando a não existência de ficha cristalográfica para esse material

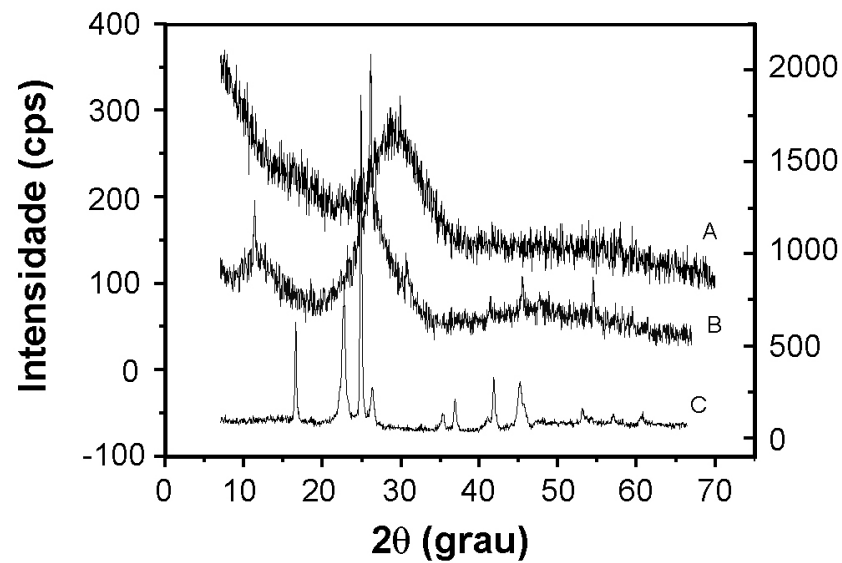

Figura 1: Difratograma da matriz inorgânica preparada via óxido de nióbio (A), com tratamento térmico a $600{ }^{\circ} \mathrm{C}$ (B) e fosfato de nióbio com tratamento térmico a $600{ }^{\circ} \mathrm{C}(\mathrm{C})$.

[Figure 1: X-ray diffraction patterns inorganic matrix prepared by niobium oxides $(A)$, with thermal treatment at $600{ }^{\circ} \mathrm{C}(B)$ and niobium phosphate $(C)$.]

na forma hidratada. Portanto, fez-se o tratamento térmico no material a $600{ }^{\circ} \mathrm{C}$ por $6 \mathrm{~h}$, obtendo-se assim, a matriz inorgânica na forma anidra (Fig. 1B) para comparação com a ficha cristalográfica existente (JCPDS19-866) do fosfato de nióbio anidro (Fig. 1C). Observou-se após o tratamento térmico que o material manteve se pouco cristalino [24]. Assim podemos dizer que a matriz inorgânica obtida não é o fosfato de nióbio.

A Fig. 2 apresenta a curva TG/DTG do material inorgânico com uma perda de massa de 15,3\% apenas em uma etapa no intervalo entre a temperatura ambiente e $555^{\circ} \mathrm{C}$, decorrente da eliminação das moléculas de água existentes no composto, com resíduo de $85 \%$. A literatura [25] apresenta uma curva TG para o fosfato de nióbio, podendo-se observar perda de massa em duas etapas entre a temperatura ambiente e $555{ }^{\circ} \mathrm{C}$, com resíduo de $82 \%$. Analisando-se comparativamente a curva TG do material adsorvente (Fig. 2) com a curva TG existente na literatura [25] confirma-se não ser o mesmo material. A curva DTG

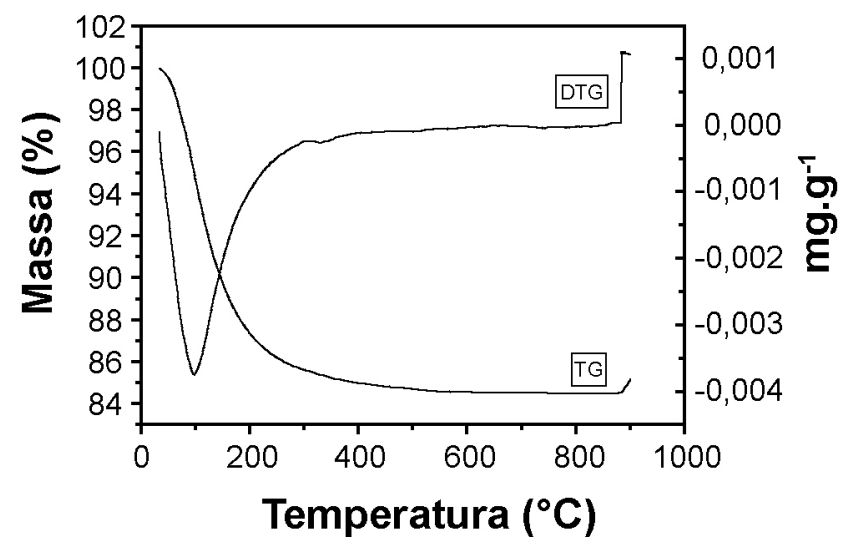

Figura 2: Curvas TG/DTG do material adsorvente desidratado. [Figure 2: TG/DTG curves of the anhydrous adsorbent material.] 
Tabela I - Resultados das curvas TG/DTG da matriz inorgânica hidratada, com as temperaturas correspondentes a velocidade máxima de perda de massa na curva DTG $(\mathrm{dm})$ no intervalo de temperatura $(\Delta \mathrm{T})$ com perdas de massa na curva TG (mp) e o resíduo (R).

[Table I - Result of TG/DTG curves forhydrous inorganic matrix, with the temperatures at mass loss in DTG curves $(d m)$ in the temperatures range $(\Delta T)$, mass loss in $T G$ curves and residue.]

\begin{tabular}{ccccc}
\hline Material & $\mathrm{m}(\%)$ & $\Delta \mathrm{T}\left({ }^{\circ} \mathrm{C}\right)$ & $\mathrm{dm}\left({ }^{\circ} \mathrm{C}\right)$ & $\mathrm{R}(\%)$ \\
\hline Matriz Inorgânica & 15,26 & $\begin{array}{c}\text { Tamb.- } \\
500\end{array}$ & 97 & 84,74 \\
\hline
\end{tabular}

mostra que a velocidade de maior perda de massa ocorre em $97{ }^{\circ} \mathrm{C}$. A Tabela I apresenta os resultados da análise de TG do material preparado.

Para a matriz inorgânica preparada a partir do pentóxido de nióbio, a área superficial encontrada foi de $10 \mathrm{~m}^{2} / \mathrm{g}$. Os resultados de área superficial apresentados na literatura para alguns silicatos naturais, como a crisotila [26], montmorillonita, vermiculita [27] mostram-se concordantes com o resultado encontrado neste trabalho. O mesmo pode ser afirmado para algumas esmectitas sódicas sintéticas [28].

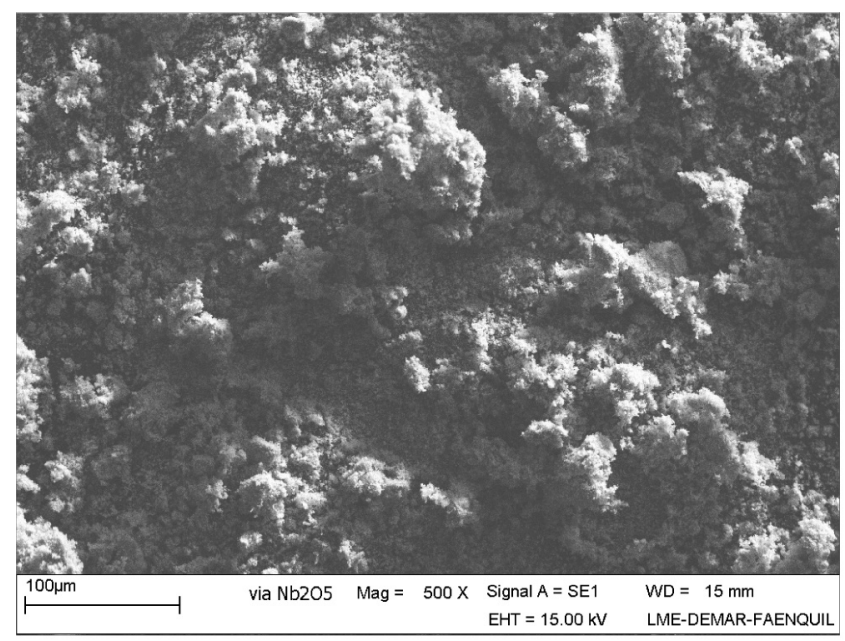

Figura 3: Micrografia do material adsorvente.

[Figure 3: Micrographs of the hydrous materials adsorbent.]

A Fig. 3 mostra a micrografia para a matriz inorgânica estudada neste trabalho. Podem-se observar pequenos aglomerados com pequenos poros sem geometria definida.

A composição química do material foi determinada por espectrometria de energia dispersiva (EDS) para determinar a composição química do composto, conforme na Tabela II. Os resultados da análise elementar pontual por EDS, que mostra a presença dos elementos silício e potássio nos materiais preparados. Usou-se cadinho de porcelana para a fusão alcalina do carbonato de potássio com pentóxido de nióbio na preparação do niobato de potássio precursor da matriz inorgânica. Portanto o silício encontrado na análise de EDS tem como origem o cadinho de porcelana utilizado no processo de fusão, enquanto que o potássio encontrado é oriundo do fundente utilizado. Na preparação do material esperava-se a proporção $\mathrm{Nb}: \mathrm{P}$ (1:2), o que não ocorreu conforme pode ser observado pelos resultados de EDS, apresentados na Tabela II. Por outro lado a presença de silício é cerca de três vezes a de fósforo em porcentagem atômica. Sabe-se que nos aluminossilicatos, os íons alumínio podem substituir os íons silício nos sítios tetraédricos, por apresentarem raios iônicos similares [29]. De forma similar, pode-se imaginar ter ocorrido na preparação da matriz inorgânica, uma substituição de fósforo por silício na estrutura. Com isso, para cada átomo de silício entrando na estrutura no lugar do fósforo, ocorrerá deficiência de unidade de carga positiva, gerando uma estrutura com carga negativa que pode ser balanceada pela entrada de cátions, tais como $\mathrm{Na}^{+}, \mathrm{K}^{+}, \mathrm{Ca}^{2+}, \mathrm{Sr}^{2+}$ etc.. Embora estes cátions não façam parte da estrutura de rede, eles permanecem ligados nos interstícios através de interações eletrostáticas [30]. Dessa forma a presença de $\mathrm{K}^{+}$confirmada pela análise de EDS é justificada pelo balanceamento de cargas necessário para a formação do composto.

Tabela II - Composição química da matriz inorgânica por EDS. [Table II - Chemical composition of the matrix inorganic for EDS.]

\begin{tabular}{|c|c|c|}
\hline \multirow{2}{*}{ Elemento } & \multicolumn{2}{|c|}{$\begin{array}{l}\text { Matriz inorgânica obtida } \\
\text { via óxido de nióbio }\end{array}$} \\
\hline & $\%$ Massa & \% Atômica \\
\hline $\mathrm{O}$ & 41,96 & 71,36 \\
\hline $\mathrm{Nb}$ & 35,00 & 10,28 \\
\hline $\mathrm{P}$ & 3,01 & 2,65 \\
\hline K & 13,80 & 9,63 \\
\hline $\mathrm{Si}$ & 6,25 & 6,08 \\
\hline
\end{tabular}

Para o estudo da adsorção no presente trabalho, fez-se uma modificação na metodologia descrita por Sheilam e Pinfold [31], substituindo-se o solvente 1,2-dicloroetano por metil isobutil cetona (MIBK). Assim, foi necessário verificar o tempo mínimo de adsorção, a faixa de concentração de trabalho, o limite de detecção da metodologia e a reprodutibilidade da técnica analítica. No estudo de adsorção e intercalação é importante se conhecer o tempo necessário de contato entre a solução contendo a espécie a ser adsorvida e o material adsorvente até que se obtenha a maior eficiência de adsorção, ou de remoção do íon. Dessa forma, alguns tempos de contato entre a matriz e o adsorvente foram estabelecidos e calculada a quantidade (qe) do $\mathrm{CTA}^{+}$adsorvido na matriz inorgânica. A quantificação das concentrações do CTAB, antes e depois do processo de adsorção, foi determinada pela

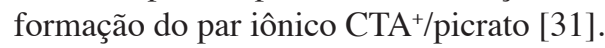

Para a realização dos experimentos de adsorção utilizouse o tempo de $1 \mathrm{~h}$ de agitação (maior adsorção) conforme estudo realizado para definição do tempo de adsorção (Tabela III). As Figs. 4 e 5 apresentam os dados experimentais de 
Tabela III - Quantidade $(q)$ de $\mathrm{CTA}^{+}$adsorvida na matriz inorgânica para diferentes tempos $(t)$ de agitação.

[Table III - Amount (q) of CTA ${ }^{+}$adsorption in the inorganic matrix for different agitation times $(t)$.]

\begin{tabular}{ccccc}
\hline $\mathrm{t}(\mathrm{h})$ & 1 & 3 & 5 & 7 \\
\hline $\mathrm{q}\left(\mathrm{mg} \cdot \mathrm{g}^{-1}\right)$ & 9,56 & 9,41 & 9,47 & 9,42 \\
\hline
\end{tabular}

adsorção, segundo as isotermas de Langmuir e Freundlich. As constantes dessas isotermas foram determinadas por regressão linear das equações linearizadas e estão listadas na Tabela IV em diferentes valores de pH. A Fig. 4 apresenta as isotermas de adsorção de Langmuir para matriz inorgânica em $\mathrm{pH}=3,0,5,6$ e 9,6 .

A Fig. 5 apresenta as isotermas de Freundlich para matriz inorgânica em $\mathrm{pH}=3,0,5,6$ e 9,6.

Neste estudo, as constantes das isotermas caracterizam os parâmetros de adsorção do material adsorvente [6]. Os dados foram determinados através das equações (1), (2) e (3). Pelo parâmetro $R_{L}$ de Langmüir (Tabela IV), pode-se constatar que a adsorção do surfatante na matriz inorgânica

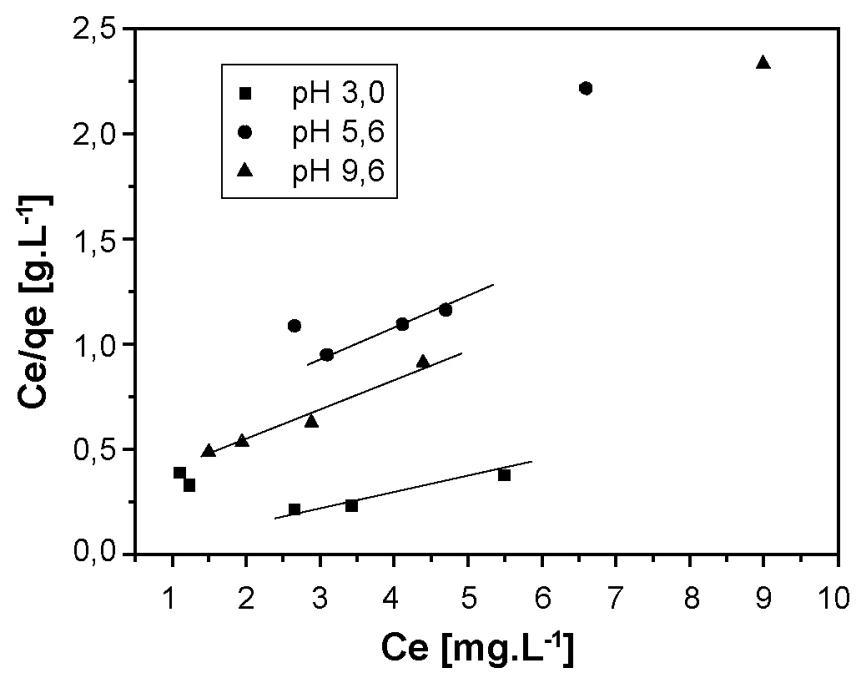

Figura 4: Isoterma de Langmuir para matriz inorgânica em pH 3,0, 5,6 e 9,6 .

[Figure 4: Langmuir adsorption isotherm for inorganic matrix in pH 3.0, 5.6 and 9.6.] em pH's 3,0; 5,6; 9,6 é favorável $\mathrm{R}_{\mathrm{L}}\left(0<\mathrm{R}_{\mathrm{L}}<1\right)$. A capacidade de adsorção máxima $\left(\mathrm{Q}_{\mathrm{o}}\right)$ varia em função do $\mathrm{pH}$ da solução do surfatante. Observa-se que em $\mathrm{pH}=5,6$ da solução de CTAB obteve-se $Q_{0}=7,486 \mathrm{mg} \cdot \mathrm{g}^{-1}$, em $\mathrm{pH}=9,6 \mathrm{Q}_{\mathrm{o}}=9,938$ $\mathrm{mg} \cdot \mathrm{g}^{-1}$ e em $\mathrm{pH} 3,0 \mathrm{Q}_{\mathrm{o}}=16,526 \mathrm{mg} \cdot \mathrm{g}^{-1}$ (maior adsorção) adsorção favorecida para o $\mathrm{CTA}^{+}$devido a presença de carga negativa na superfície do suporte gerada pela substituição do fósforo pelo silício na formação da matriz inorgânica. Pelo parâmetro $n$ de Freundlich pode-se constatar que a adsorção do surfatante na matriz inorgânica em pH's 3,0; 5,6; 9,6 não é favorável $\mathrm{n}(2<\mathrm{n}<10)$ porém os dados se ajustam ao modelo $(r=0,999)$. A adsorção do surfatante CTAB em perlita, investigando o efeito da força iônica, $\mathrm{pH}$ e temperatura foi estudada, utilizando as isotermas de Langmuir e Freundlich para interpretar os resultados [32]. Pelos parâmetros de Langmuir encontrou-se para o valor de $\mathrm{pH} 3,0, \mathrm{Q}_{\mathrm{o}}=3,02 \mathrm{mg} \cdot \mathrm{g}^{-1}$, para $\mathrm{pH}=5,0, \mathrm{Q}_{\mathrm{o}}=3,17 \mathrm{mg} \cdot \mathrm{g}^{-1}$ e para pH $9,0 \mathrm{Q}_{0}=3,90 \mathrm{mg} \cdot \mathrm{g}^{-1}$. Comparando-se os dados da literatura [32] com os dados obtidos nesse trabalho (Tabela IV) observa-se que a capacidade de adsorção do material inorgânico preparado foi maior em todos os $\mathrm{pH}$ estudados.

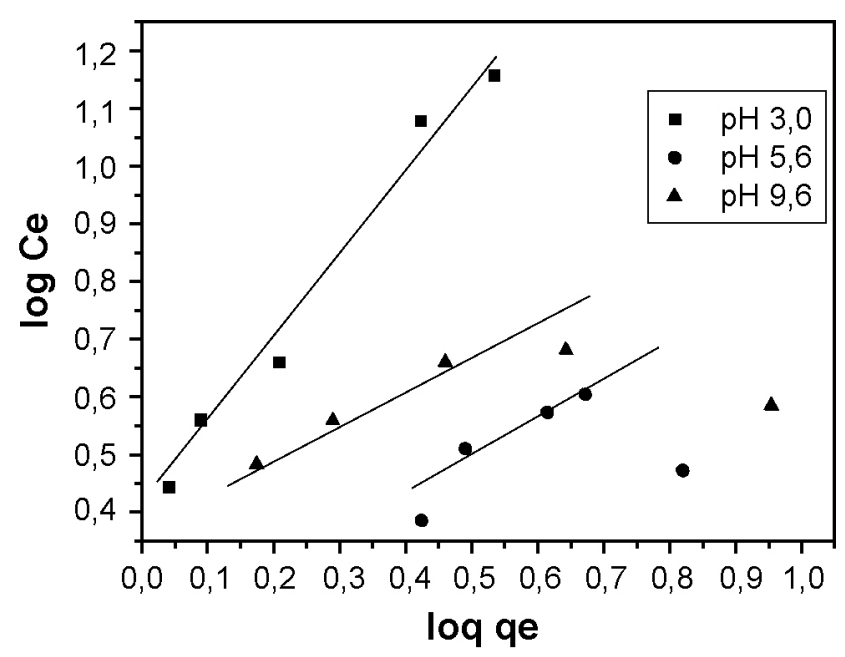

Figura 5: Isotermas de Freundlich para a matriz inorgânica em 3,0, 5,6 e 9,6 .

[Figure 5: Freundlich adsorption isotherm for inorganic matrix in pH 3.0, 5.6 and 9.6.]

Tabela IV - Parâmetro do modelo da isoterma de Freundlich e Langmuir para o íon $\mathrm{CTA}^{+}$na matriz inorgânica em vários $\mathrm{pH}$.

[Table IV - Parameters of the isotherm model of Langmuir and Freundlich for ion $\mathrm{CTA}^{+}$in inorganic matrix at different $\mathrm{pH}$.]

\begin{tabular}{cccccccc}
\hline \multirow{2}{*}{$\begin{array}{c}\text { Matriz } \\
\text { Inorgânica }\end{array}$} & \multicolumn{3}{c}{ Parâmetros de Freundlich } & \multicolumn{5}{c}{ Parâmetros de Langmuir } \\
\cline { 2 - 8 } & $\mathrm{K}_{\mathrm{f}}\left(\mathrm{mg} \mathrm{g}^{-1}\right)$ & $\mathrm{n}$ & $\mathrm{r}$ & $\mathrm{Q}_{0}\left(\mathrm{mg} \mathrm{g}^{-1}\right)$ & $\mathrm{b}\left(\mathrm{L} \mathrm{mg}^{-1}\right)$ & $\mathrm{R}_{\mathrm{L}}$ & $\mathrm{r}$ \\
\hline pH 3,0 & 2,506 & 0,675 & 0,999 & 16,52 & 1,274 & 0,015 & 0,999 \\
pH 5,6 & 1,812 & 1,938 & 0,998 & 7,486 & 0,246 & 0,194 & 0,999 \\
pH 9,6 & 2,393 & 1,624 & 0,999 & 9,938 & 0,296 & 0,167 & 0,999 \\
\hline
\end{tabular}




\section{CONCLUSÕES}

A forma de preparação do material acarretou mudanças físicas significativas na estrutura, podendo observar a presença dos elementos silício e potássio. A presença de impurezas ( $\mathrm{Si}$ e $\mathrm{K}$ ) na estrutura do composto gerou um material não cristalino. Pelos resultados de DRX e TG pôde-se constatar que o material preparado não é o fosfato de nióbio puro. A matriz inorgânica adsorvente apresentou comportamento favorável no estudo da adsorção do surfatante catiônico (CTAB), segundo o modelo de isoterma de Langmuir. A melhor adsorção ocorreu em pH 3,0. Os resultados de adsorção não foram favoráveis segundo o modelo de isoterma de Freundlich, porém os dados se ajustam a este modelo.

\section{NOMENCLATURA}

$\mathrm{C}_{\mathrm{e}}$ : concentração do íon após atingir o equilíbrio do processo de adsorção $\left(\mathrm{mg} . \mathrm{L}^{-1}\right) ; \mathrm{q}_{\mathrm{e}}$ : quantidade de íon adsorvido na espécie adsorvente $\left(\mathrm{mg} . \mathrm{g}^{-1}\right) ; \mathrm{Q}_{0}$ : constante relacionada com a capacidade máxima de adsorção do material adsorvente (mg.g $\left.\mathrm{g}^{-1}\right) ; \mathrm{R}_{\mathrm{L}}$ : característica essencial da isoterma de Langmuir (adimensional); $\mathrm{K}_{\mathrm{f}}$ : constante relaciona com a capacidade de adsorção; $\mathrm{n}$ : constante relacionada a intensidade de adsorção.

\section{AGRADECIMENTOS}

Os autores agradecem o apoio financeiro da CAPES.

\section{REFERÊNCIAS}

[1] D. Bayot, M. Devillers, Coordination Chem. Rev. 250 (2006) 2610.

[2] A. E. Lewandowska, M. A Bañares, Catalysis Today 118 (2006) 323.

[3] A. N. Zelikman, O. E. Krein, G. V. Samsonov, Metallurgy of rare metals, Israel Program for Scientific Translation, Jerusalem, Israel (1996) p.101.

[4] CBMM, Companhia Brasileira de Metalurgia e Mineração. Nióbio: Usos e Usuários,

http:// www.cbmm.com.br/portug/surces/usesf-uses.htm, acessado outubro (2005).

[5] G. V. Tagliaferro, M. L. C. P Silva, G. L. P Silva, Quim. Nova 28, 2 (2005) 250.

[6] A. L. C. Peixoto, M. L. C. P Silva, G. L. J. P. Silva, Cerâmica 52, 324 (2006) 249.

[7] A. C. Antunes, S. F. Domingues, L. F Moura, Quim. Nova 16 , 6 (1993) 521.
[8] D. N. Villela F., M. L. C. P. Silva, G. L. P. Silva, Mater. Res. 5, 1 (2002) 71.

[9] M. J. Serafim, M. C. A. Nono, M. L. C. P Silva, G. L. J. P Silva, Anais $12^{\circ}$ Cong. Bras. Eng. Ci. Mater., Águas de Lindóia, SP (1996) 105.

[10] M. Miranda, M. L. C. P. Silva, H. F. Castro, XV Cong. Bras. Eng. - COBEQ, Curitiba, PR (2004).

[11] M. L. C. P. Silva, G. L. J. P. Silva, E. A. C. Perez, G. V. Tagliaferro, Anais Assoc. Bras. Quím. 50, 2 (2001) 83.

[12] M. Miranda, M. L. C. P. Silva, H. F. Castro, J. Chem. Technol. Biotecnol. 81, 4 (2006) 566.

[13] P. C. Pavan, E. L. Crepaldi, J. B. Valim, J. Colloid Interface Sci. 229 (2000) 346.

[14] F. Wypych, G. G. C. Arizaga, Quim. Nova 28, 1 (2005) 24.

[15] M. L. Mignoni, C. B. C. Pergher, Quim. Nova 30, 1 (2007) 445

[16] L. L. M Sales, A. G. Souza, L. E. B. Soledade, I. M. G. Santos, Quim. Nova 30, 1 (2007) 70.

[17] D. A. Fungaro, J. C. Izidoro, Quim. Nova 29, 4 (2006) 735 .

[18] D. A. Fungaro, M. G. Silva, Quim. Nova 25, 6B (2002) 1081.

[19] D. A. Fungaro, J. C. Izidoro, R. S. Almeida, Eclética Quím.30, 2 (2005).

[20] M. M. Nassar, K. T. Ewida, E. E. Ebrahiem, Y. H. Magdy, Adsorption Sci. \& Technol. 22 (2004) 25.

[21] M. M. Abou-Mesalam, Colloids Surfaces A 225 (2003) 85.

[22] R. B. Hahn, J. Am. Chem. Soc. 73 (1951) 5091.

[23] S. Brunauer, P. Emmet, E. Teller, J. Am. Chem. Soc. 60 (1938) 309.

[24] C. R. Rambo, L. Ghussn, F. F Sene, J. R. Martinelli, J. Noncrystalline Solids 352 (2006) 3739.

[25] A. C. Antunes, S. F. Dominguez, L. F. Moura, Quim. Nova 16 (1993) 521.

[26] I. B. Valentim , I. Joekes, Colloids Surfaces A 290 (2006) 106.

[27] J. Ravichandran , B. Sivasankar, Clays Minerals 45, 6 (1997) 854.

[28] T. Kasama, Y. Watanabe, H. Yamada, T. Murakami, Appl. Clay Sci. 25 (2004) 167.

[29] M. Qureshi, K. G. Varshney, Inorganic ion exchangers in chemical analysis, Boston, EUA (1991) 282.

[30] P. F. Shiver, P. Atkins, Química Inorgânica, $3^{\text {a }}$ Ed., Porto Alegre, RS (2003).

[31] I. Sheiham, T. A. Pinfold, Analyst. 94 (1969) 387.

[32] M. Alkan, M. Karadas, M. Dogan, O. Demirbas, J. Colloid Interface Sci. 291 (2005) 309.

(Rec.01/04/2008, Rev. 27/08/2008, Ac. 18/12/2008) 